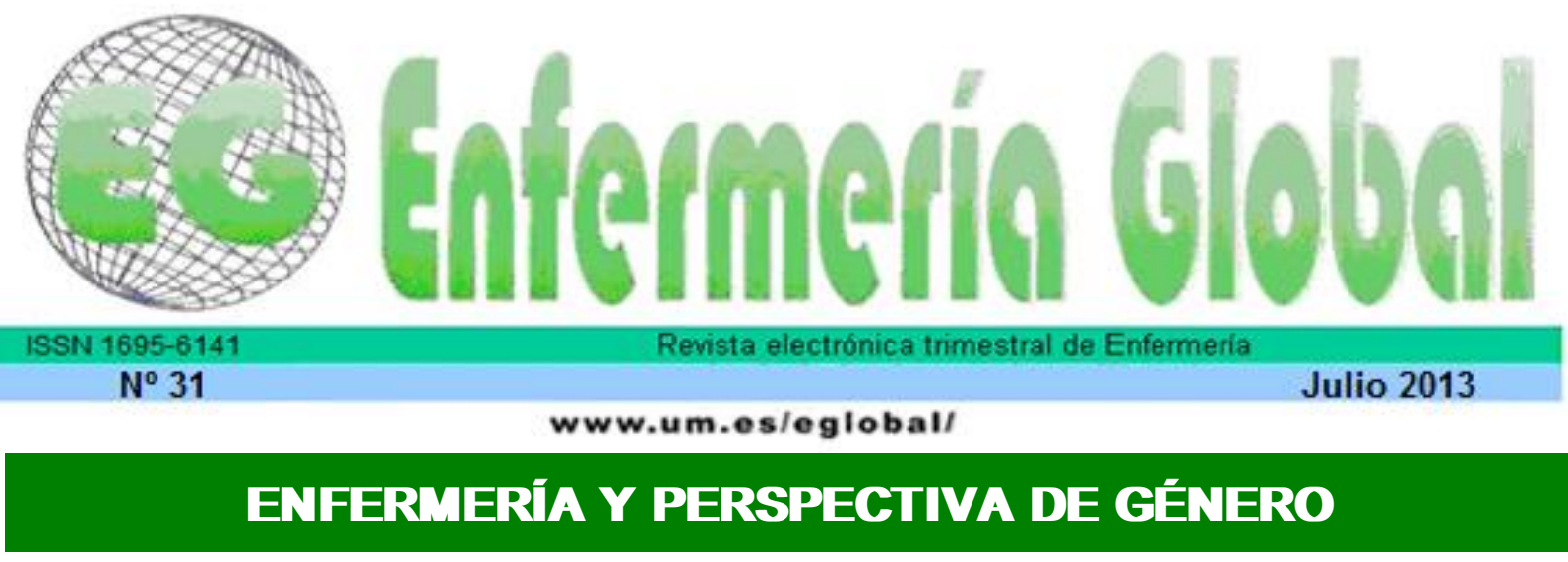

\title{
Identificación de las fortalezas, preocupaciones y necesidades educativas del Servicio Rural de Agresión sexual en las comunidades rurales y aborígenes de Alberta (Canadá)
}

Identifying Rural Sexual Assault Service Strengths, Concerns and Educational Needs in rural and Aboriginal communities Alberta, Canada

\section{*Jakubec, Sonya L. ${ }^{* *}$ Carter-Snell, Catherine J. ${ }^{* * *}$ Ofrim, Jenny ****Skanderup, Judy}

*RN, PhD (c), Mount Royal University. E-mail: sjakubec@mtroyal.ca ${ }^{* *} \mathrm{RN}$, PhD, Mount Royal University ${ }^{* * *}$ RSW, MSW, Association of Alberta Sexual Assault Services ${ }^{* * *} \mathrm{RN}, \mathrm{MN}, \mathrm{NP}$, Alberta Health Services. Canadá.

Palabras clave: agresión sexual, salud rural, salud de la mujer, victimización secundaria, entrevistas de grupo.

Keywords: Sexual Assault; Rural Health; Women's Health; Secondary Victimization; Focus Group.

\section{RESUMEN}

Las mujeres en las comunidades rurales no reciben regularmente la atención integral de salud debida después de haber sufrido agresiones sexuales, lo que resulta en un aumento de las tasas de enfermedad mental, abuso de sustancias, revictimización, y problemas de salud crónicos. Además, las mujeres corren el riesgo de una victimización secundaria, de una estigmatización y de una revictimización derivada de las respuestas de los otros a la agesión. La victimización secundaria aumenta cuando las víctimas deben ser transportadas fuera de la comunidad rural para su tratamiento, debido a las demoras en los servicios, cuando los profesionales reaccionan de forma negativa hacia ellas, o sencillamente prestan unos servicios incompletos. Un estudio de investigación se hace necesario para abordar estos riesgos y comprender la necesidad de recursos educativos para los trabajadores que están a cargo de la crisis en las comunidades rurales y de aborígenes. Los hallazgos de las entrevistas de grupo con profesionales interdisciplinarios en las zonas rurales de Alberta, Canadá, identificaron algunas fortalezas, pero también revelan desafíos y la prioridad de una educación necesaria para aquellas personas que cuidan de las víctimas de agresión sexual.

\section{ABSTRACT}

Women in rural communities do not regularly receive comprehensive health care following sexual assaults, resulting in increased rates of mental illness, substance abuse, re-victimization, and chronic health problems. Additionally, women are at risk for secondary victimization, the stigmatization and revictimization that results from the responses of others to the assault. Secondary victimization is amplified when victims must be transported out of a rural community for treatment, receive delays in services, when professionals react negatively towards them, or provide incomplete services. A research 
study sought to find ways of addressing these risks and understanding the educational resources needed for crisis care workers in rural and Aboriginal communities. The findings from focus group interviews with interdisciplinary professionals in rural Alberta, Canada, identified strengths, challenges and priority educational needs for those caring for sexual assault victims.

\section{INTRODUCCIÓN}

El abuso sexual es un acto traumático de violencia que altera la vida. Internacionalmente, los estudios basados en población muestran unas cifras alarmantes de mujeres en países tanto desarrollados como subdesarrollados. Con diferentes estrategias de registro estadístico de informes, algunos países informan de una prevalencia de abuso sexual tan bajo como $4 \%$, mientras que otros países informan tasas de agresión sexual superiores al $44 \%$ de todas las mujeres. Al menos se ha abusado de la mitad de las mujeres canadienses a los 16 años, sin embargo, menos del $10 \%$ informan a la policía y sólo el $30 \%$ pide atención médica ${ }^{2}$.La severidad y cifras de abuso sexual en comunidades rurales y aborígenes son difíciles de determinar, pero se espera que sean incluso más altas dada la predominancia de no abusos sexuales y miedos de informarlos en una comunidad pequeña. ${ }^{3}$ Las mujeres de las que se abusa por alguien que ellas conocen tienen una posibilidad significativamente menor de que informen. ${ }^{4}$ Las mujeres aborígenes canadienses, de las cuales la mitad viven en áreas rurales, tienen unas cifras significativas mayores de abusos sexuales y es más probable que sean ingresadas por sus lesiones. ${ }^{5}$

El abuso sexual está asociado con muchas consecuencias que alteran la vida. Más de la mitad de las mujeres que han sido víctimas de un abuso desarrollan síndromes de estrés postraumático (SEP) así como otros problemas tales como la depresión, el uso de sustancias, problemas crónicos de salud e intentos de suicidio. ${ }^{6,7}$ Estas consecuencias resultan en un incremento de la utilización de los servicios de la salud, dificultades en el funcionamiento laboral 0 escolar, relaciones familiares desestructuradas y un desarrollo económico de la comunidad desigual. La tasa de SEP es incluso más alta si las mujeres se enfrentan a mayores situaciones de estrés tras el abuso sexual, un factor conocido como segunda victimización. ${ }^{8}$

La segunda victimización, también llamada "segunda violación", ${ }^{9}$ ocurre cuando las víctimas experimentan más estrés o trauma cuando piden ayuda. Puede ocurrir tras sentimientos de culpabilidad, técnicas insensibles de comunicación, retrasos en el cuidado, falta de credibilidad, vergüenza, estigmatización o de haber minimizado la experiencia por otras personas. ${ }^{10}$

La familia, amigos y medios de comunicación juegan un papel en la segunda victimización, sin embargo, aquellos en los que se confía para ofrecer ayuda profesional como por ejemplo la policía, enfermeros, médicos y servicios sociales no están exentos de las creencias de culpabilidad de la víctima y los comportamientos que contribuyen a la segunda victimización. ${ }^{11}$ Estas respuestas, o incluso el miedo a estas respuestas, tienen un impacto en el hecho de que las víctimas pidan ayuda, resultando en reticencias para el acceso médico y las intervenciones sociales y legales. ${ }^{12}$

La segunda victimización también puede ocurrir si las víctimas reciben un cuidado incompleto o fragmentado, si su caso no es procesado por los tribunales o si el asaltante recibe una sanción mínima. Esto supone riesgos sociales e individuales relacionados con la falta de comunicación cuando las víctimas consideran que no van 
a ser tomadas en serio o que serán culpadas por el abuso ${ }^{13,14}$. Reconociendo la magnitud del problema, la Organización Mundial de la Salud lanzó una iniciativa de investigación de la violencia sexual en 2004, con un interés considerable en desarrollar un conocimiento de las mejores prácticas para la salud y las intervenciones legales tras el abuso. ${ }^{15} \mathrm{El}$ propósito de este estudio fue identificar un modo de dirigir los riesgos de una segunda victimización dentro de la práctica rural, construyendo sobre fuerzas ya existentes, y comprendiendo los recursos educacionales necesarios para la crisis de cuidados en los trabajadores en comunidades rurales y aborígenes.

\section{ANTECEDENTES}

\section{Contexto rural}

Hay una serie de factores que aumentan el riesgo de una segunda victimización en mujeres de comunidades rurales y aborígenes, incluyendo: aislamiento, tener que permanecer cerca del asaltante, servicios limitados y falta de transporte. ${ }^{16}$ El objetivo de nuestro estudio, sin embargo, fue un factor de riesgo que pudo ser dirigido por profesionales ofreciendo servicios en comunidades rurales.

\section{a) Limitaciones rurales}

Las mujeres han descrito barreras para informar sobre el abuso sexual a la policía o a los profesionales sanitarios debido al miedo de rechazo o a que no se las crea. ${ }^{2}$ Las mujeres también se muestran reticentes a implicarse con la policía o tribunales ${ }^{17}$ particularmente si el asaltante es conocido por ellas ${ }^{2}$. La última afecta especialmente a mujeres que viven en comunidades rurales donde pueden encontrarse con el asaltante. Las mujeres que viven en comunidades rurales muy remotas pueden necesitar informar sobre su abuso a la policía para poder acceder a un servicio de salud fuera de la comunidad en transporte; incluso aunque ellas no quisieran hacer un informe policial ${ }^{18 .}$ Esto les provoca una elección más: si contar 0 no sus circunstancias.

\section{b) Servicios rurales}

Las mujeres que informaron a la policía o pidieron ayuda sanitaria también manifestaron factores de estrés relacionados con la petición de la misma. Algunos de estos factores incluían: una lenta respuesta policial, servicios limitados, retrasos en el cuidado recibido, falta de anonimato, brechas en la confidencialidad, falta de conocimiento del cuidado de los abusos sexuales por los proveedores de salud y una actitud insensible o condescendiente de las personas a las que se accede para pedirles ayuda. ${ }^{19}$ Algunos centros urbanos norteamericanos han introducido examinadores enfermeros especializados en abuso sexual, en inglés conocidos con las siglas SANEs. SANEs ofrecen una intervención en el momento de crisis y apoyo, así como una amplia variedad de servicios de cuidados y, si la víctima lo solicita, facilitar la intervención policial y recopilación de pruebas. Esta práctica está asociada con un aumento de un cuidado completo, una mejora de los resultados del paciente, una mejora de la calidad de recopilación de pruebas y un incremento de deseo para informar sobre su abuso a la policía. ${ }^{20}$ Los SANEs no están disponibles en todas las áreas urbanas de Alberta, o en cualquier comunidad rural. La financiación, el entrenamiento y el mantenimiento de las destrezas son todas las dificultades en la 
provisión de servicios especializados. Esto es especialmente cierto en áreas rurales donde menos mujeres piden cuidados de salud tras abusos sexuales.

Las mujeres rurales y aborígenes que buscan ayuda tras un abuso sexual normalmente se acercarán al servicio de emergencias o clínica más próximo. En estos centros de atención de salud, a los pacientes de agresión sexual se les asigna normalmente un grado triaje de dos o tres en la Escala de Triaje Canadiense.$^{21}$ Esta designación significa que las pacientes deben ser vistas entre 30-120 minutos dependiendo de otros factores tales como las molestias a que pueden contribuir a esa situación. Normalmente, las pacientes en un lugar rural esperarán mucho más tiempo si la plantilla del servicio de emergencias está formada por un solo médico de urgencias. Pueden pasar más de dos o tres horas hasta que el médico pueda estar libre para la completa entrevista y reconocimiento. En un ámbito rural, con un entrenamiento limitado en abusos sexuales, hay percepciones de que este bloque de tiempo es requerido para llevar a cabo la evaluación y recopilación de pruebas y que esto solo lo puede llevar a cabo el médico. Desgraciadamente, esto significa que las mujeres pueden esperar durante varias horas antes de ser entrevistadas y examinadas, una espera que contribuye a su estrés. Estudios americanos han revelado que las mujeres que han sufrido un abuso sexual padecen más estrés después de haber informado a la policía o a los servicios de la salud del que los profesionales pueden advertir, con lo que la gran mayoría no pediría ayuda si volviesen a ser asaltadas. ${ }^{22}$ Entre las fuentes que contribuyen a su estrés se incluían la vergüenza, culpabilidad o falta de credibilidad, sintiéndose estigmatizadas, experimentando retrasos o recibiendo un cuidado incompleto.

Si las mujeres informasen de sus asaltos, facilitando la implicación policial y la recopilación de pruebas sería solo una piedra angular de unos servicios completos de abusos sexuales. El conjunto de recopilación estandarizado de pruebas que se usa en el sur de Alberta es normalmente el de la Real Policía Montada Canadiense, un conjunto que está actualmente siendo actualizado debido a varias invasivas y obsoletas prácticas y enseñanzas. Prácticas y compresiones de conceptos locales tales como cadena de custodia varía debido al único conocimiento y experiencia de la policía y los profesionales. Algunos policías interpretan las normas en el sentido de que tienen que permanecer en la habitación con la mujer durante la recopilación de pruebas. Del mismo modo, los conceptos de cuidado forense no se incluyen rutinariamente ni en la educación enfermera ni en la médica, contribuyendo aún más a las variaciones en la práctica y las expectativas sobre quién puede y debe llevar a cabo los aspectos de la evaluación de la salud y de la documentación.

Las facilidades rurales pueden elegir el traslado de las mujeres a los centros urbanos para que sean atendidas por los servicios del SANE, pero esto tiene también sus desventajas. El traslado de las mujeres de la comunidad a los centros urbanos ha estado asociado con un incremento del sufrimiento de la víctima incluyendo: mayores retrasos, aislamiento de la ayuda de la comunidad, ${ }^{23,2}$ así como pérdida potencial de pruebas y retirada de los dispositivos que estaban preparados por la policía del área rural. ${ }^{24}$ Las mujeres del entorno rural sufrirían una falta de sensibilidad cultural y de conciencia sobre sus situaciones más aisladas si ellas fuesen tratadas fuera de la comunidad. ${ }^{2}$ De un modo similar, las mujeres aborígenes se mostraban reticentes a pedir ayuda fuera de sus comunidades debido a la falta de sensibilidad y a sus preocupaciones culturales. $^{25}$ 


\section{Búsqueda de soluciones}

A pesar de las preocupaciones sobre la confidencialidad, el anonimato y los temas de proximidad a su asaltante, generalmente hablando, las mujeres informaron que preferían ser tratadas en sus propias comunidades. ¿Cómo, entonces, pueden los centros rurales ofrecer un cuidado sensible, completo y multidisciplinar de un modo que sea constructivo a partir de las fuerzas y fuentes ya existentes? El uso de los SANES en comunidades rurales no es una opción viable, ya que un número limitado de casos informaron sobre descartar la oportunidad para las enfermeras de obtener la experiencia requerida, y un presupuesto y plantilla de enfermería disponible limitado hacen que sea difícil implementar este modelo. Lamont ${ }^{2}$ recomienda un modelo de servicios interdisciplinados centrados en la víctima que ha sufrido un abuso sexual en comunidades rurales y remotas, incluyendo la policía, los consejeros y los profesionales de la salud.

Nosotros afirmamos que es posible en muchos casos ofrecer un cuidado sensible y completo a las víctimas que han sufrido abusos sexuales dentro de su propia comunidad. Esto debe ser respaldado a través de la provisión de recursos educativos y/o ayuda en tiempo real accedida desde una distancia cuando las víctimas solicitan servicios. No se puede asumir que las mismas estrategias para reducir la segunda victimización se aplicarán en todas las comunidades rurales o aborígenes. Para que sea viable, es importante que las soluciones vengan de la comunidad y estén confeccionadas para los recursos de cada comunidad. ${ }^{2}$ Además, desconfiar de los forasteros y de las soluciones que provienen de áreas urbanas son barreras adicionales para que las mujeres rurales informen de su abuso. Por estas razones, los investigadores que están involucrados en nuestro estudio intentan identificar las necesidades educativas y los apoyos esenciales requeridos por los proveedores de servicios en comunidades rurales aborígenes. Este artículo se centra en el análisis más profundo de estos tres casos de entrevistas de grupos en los cuales los puntos fuertes, retos y posibles soluciones fueron explorados con expertos informantes de 3 comunidades rurales en el sur de Alberta, Canadá.

\section{MÉTODO: Entrevistas de grupo focalizadas}

\section{Enfoque teórico}

El enfoque de las entrevistas de grupo focalizadas y análisis en profundidad era un punto de vista crítico feminista de una teoría educativa anti-opresiva. ${ }^{26}$ Una perspectiva así reconoce la opresión, contextos, y el juego de poder entre las relaciones sociales y la organización. Este punto de vista es tanto consecuencia para el tema que nos atañe (abuso sexual y re-victimización) como para la noción de poder e importante organización de los contextos sociales locales rurales, entre los servicios de salud rurales y el reparto de educación profesional.

Estrategias de investigación: Método, participantes, entrevista con preguntas, ética y proceso analítico.

Guiados por críticos feministas y una teoría anti-opresiva, los investigadores invitaron a grupos de expertos informantes que trabajaban con víctimas de abusos sexuales en comunidades rurales a participar en entrevistas centradas en grupo cuyo objetivo era 
fortalecer los servicios rurales de abuso sexual. Los participantes (8-20 participantes en cada uno de los 3 grupos de entrevistas para una muestra total de 40) voluntariamente atendieron entrevistas llevadas en un centro de salud rural, un hospital rural y un centro de salud aborigen basado ruralmente, todos en el sur de Alberta, Canadá. Los sitios representaban varios tamaños de comunidad y proximidades al área urbana más cercana. Aquellos que consintieron que se les entrevistasen representaban aspectos interdisciplinares de cuidado rural de las víctimas de abusos sexuales incluyendo 15 enfermeras, 6 policías, 1 médico, 11 profesionales de servicio de asesoramiento a las víctimas, así como 4 administradores o coordinadores de servicios relacionados, y 3 aborígenes mayores.

Las entrevistas eran cada una entre 60-90 minutos y se grababan en formato digital. Se les preguntó a todos los participantes que respondieran a las mismas rondas de preguntas para determinar: 1) puntos fuertes, 2) preocupaciones, y 3) necesidades educativas primordiales, así como los métodos preferidos de ayuda o presentación de los materiales educativos de ayuda. Se obtuvo el consentimiento de todos los participantes. Una aprobación ética se obtuvo de la Universidad de Mount Royal del Tribunal Ético de Investigaciones de Sujetos Humanos.

Los datos fueron transcritos a textos. En una primera lectura de los textos, las notas se hacían de los temas principales que emergían de los datos, considerando los temas de puntos fuertes, retos y prioridades de educación. Siguió una segunda lectura del texto con anotaciones y se examinó más detalladamente, línea a línea, para facilitar un microanálisis de los datos. Temas iniciales implicados emergieron organizando los ítems relacionados a temas similares en categorías. Los datos entonces se organizaron por tablas identificando las líneas de referencias de tal modo que las categorías pudieran ser colapsadas y modificadas. ${ }^{27} \mathrm{El}$ análisis temático se aplicó a los datos de la entrevista así como los datos de las notas de campo más extensas tomadas por los dos autores principales que facilitaron las entrevistas centradas de grupo.

Este fue un análisis teórico y no inductivo. Las lentes de educación feminista antiopresiva guiaron nuestra lectura y representación de este dato, iluminando necesidades de prácticas de salud opresivas y recomendaciones de estos datos. Mientras un amplio patrón de los datos fue buscado, temas más refinados se identificaron en un proceso de investigación final de equipo para atender a principios de compromiso local, educación y prácticas anti-opresivas. Los analistas principales, en cooperación con los colaboradores del proyecto, llamados en este estudio $3^{\circ}$ y y $4^{\circ}$ autores, permitieron una revisión de la relevancia de temas estableciendo confianza. ${ }^{28,}{ }^{29}$ Este nivel de análisis también ayudó a establecer resonancia con expertos trabajando en el campo, así como los investigadores que estuvieron presentes en las entrevistas. El equipo final de análisis se centró estrechamente en el significado subyacente de cada tema entre los narradores y contextos. Éste es el significado que se presenta en los resultados que siguen a continuación.

\section{RESULTADOS}

Los resultados, para poder seguirlos, están descritos en el orden que fueron discutidos en los grupos: 1) puntos fuertes, 2) preocupaciones y 3) necesidades de recursos educativos/enfoques preferidos. 


\section{Puntos fuertes}

Los puntos de los profesionales rurales fueron encontrados en primer lugar y principalmente en una preocupación más profunda y compromiso de mujeres que habían experimentado abuso sexual. Enfoques colaborativos, consultativos, proximidad física y cercanía para ser capaz de hacer referencias y ofrecer una evaluación en la casa y una intervención donde fueron identificados todos los puntos fuertes. Esta cercanía permitió seguir en un camino que las referencias en zonas urbanas podían perder, con más atención en las necesidades emocionales y culturales inmediatas. Por último, una iniciativa arqueada y un deseo para trabajar juntos fue enfatizado.

\section{Profunda preocupación y compromiso}

La fuerte respuesta a la invitación del propio grupo focalizado fue un testamento de una profunda preocupación y compromiso en comunidades rurales para mejorar los servicios de mujeres que habían sufrido abusos sexuales. Todos los grupos focalizados fueron bien atendidos (una media de 12 participantes en cada uno de los 3 grupos). Un participante habló de la importancia de mejorar protocolos, procedimientos y calidad de cuidado:

"Estamos todos entusiasmados por poder tener alguna aportación de lo que podemos hacer, cuando necesitamos hacerlo, y hacerlo bien"

Otro participante explicó parte de su razonamiento por esta preocupación y compromiso y se preguntaron a ellos mismos las cuestiones:

"Nosotros sabemos que no estamos ofreciendo lo mejor, dadas las fuentes disponibles. ¿Pero qué podemos hacer para usar mejor nuestros recursos con entrenamiento?

Es esta profunda preocupación por mejorar los cuidados de salud y el servicio lo que nos dio el ímpetu y motivación para continuar con la educación para la administración rural y en la primera línea de los trabajadores en crisis.

\section{Enfoques consultativos}

Abrumadoramente, los terapeutas rurales tenían relaciones laborales cercanas entre y a través de las agencias de servicio para la provisión de servicios a mujeres de las que se ha abusado. Siendo familiares los unos con los otros como "vecinos" y sabiendo que cada uno podría contribuir a reforzar sus trabajos juntos. El conocimiento personal y la comunidad entre unos y otros capacitaron a los profesionales rurales para contactar entre ellos de una manera oportuna y ofrecerse ayuda en este momento sensible, emocional tanto para las víctimas como para los profesionales. Para algunos, su familiaridad habilitaba referencias más transparentes a los servicios disponibles para los servicios de seguimiento (por ejemplo, los servicios de apoyo de la víctima o de los servicios de salud mental), ya que las víctimas pueden conocer la agencia de referencia o ponerse en contacto personalmente. 
Informantes de la policía declararon que ellos estaban casi siempre en contacto con abusos sexuales. Esto era visto como un indicativo de un proceso de consulta que había alcanzado muchos beneficios para la víctima y la comunidad. Sólidas prácticas de consulta ocurrieron dentro y a través de profesionales y agencias, así como una forma de consultar a las propias víctimas.

"Nosotras hemos sido entrenadas en temas sensibles tratando la comunicación con la víctima en un modo tan apropiado como sea posible"

Esta preocupación, sensibilidad, y centrarse en la protección de la privacidad de las víctimas, fueron todo puntos fuertes identificados. A veces esta sensibilidad era expresada en la rapidez del cuidado del paciente, asegurando espacios privados para las entrevistas, expidiendo sus evaluaciones al servicio de urgencias, o través de comunicación directa. Se debatieron las formas de comunicación que se centraban solo en servicios específicos que se requerían inmediatamente, sabiendo que con las victimas que vivían en la comunidad se podían hacer referencias a otros servicios siguiendo la resolución de la situación de crisis inmediata. Un informante de los servicios de salud afirmaba:

"Nosotros intentamos no hacer demasiadas preguntas, porque tener que contestar las mismas preguntas una y otra vez, es muy traumático"

Otro informante en nuestros grupos de debate explicó:

"Nosotros normalmente obtenemos las mejores pruebas de la declaración inicial y encontramos, en mayor parte, personas que no han contado su historia cinco o seis veces antes de que hayan venido a vernos- esto ayuda a todo el mundo."

\section{Proximidad física e inmediatez}

Como resultado de la proximidad a las facilidades rurales "no estamos enviando a la víctima por todas partes...es eficiente y menos alarmante [para la víctima]". Los profesionales rurales describieron una buena probabilidad de que las víctimas recibirían seguimiento cuando la salud mental, sexual y las agencias de apoyo a las víctimas están cerca. Los servicios que estaban cerca eran una parte importante del enfoque consultativo elogiado previamente. Uno de los profesionales afirmó:

"Creo que el mecanismo más grande es el que va a trabajar bien, es la conexión entre la comunidad de la salud y el de urgencias y que estamos de hecho en el mismo edificio...es realmente conveniente....no es como si estuviésemos mandando a la víctima a un edificio diferente"

Mientras sólidas prácticas de consulta para la crisis y los servicios de seguimiento estaban disponibles en áreas rurales, los límites de la plantilla de guardia para muchas necesidades de la comunidad también eran consideraciones. El potencial de trabajo excesivo y agotamiento, particularmente considerando la carga emocional del cuidado de abuso sexual, era un conflicto potencial entre la fuerza de colaboración y los servicios de proximidad.

La sensibilidad emocional en esa primera toma de contacto con las víctimas también es reconocida por la policía y los servicios de salud. En algunos casos la policía alertaría a los trabajadores sanitarios que llegasen al centro, después la plantilla 
podría expedir la adecuada acomodación con el departamento de policía de la víctima, esquivando el puesto de triaje. En cualquier caso, la ayuda emocional inmediata fue vista como un paso hacia unos servicios de abuso sexual completos. El seguimiento y un cuidado adecuado a las fuentes referentes locales para más ayuda psicológica, ayuda inmigrante o tradicionales (Aborígenes) formas de curación también fueron factores que contribuyeron a una fuerte crisis rural de los abusos sexuales. Un informante comentó este punto fuerte en concreto:

"Lo que nosotros podemos ofrecer a través de nuestro programa es ser conscientes del aspecto cultural de cada situación que se nos plantea, y también ser capaces de comunicarnos con las víctimas de abusos sexuales a través de nuestra primera Lengua."

Ofrecer ayuda emocional inmediata también incumbe a la familia, que tendría mayor posibilidad de ser llamada como apoyos y, también para recibir ayuda, cuando los servicios están cerca. Apoyos locales disponibles preparados podrían involucrar a la familia o dar un respiro a la familia incluyendo un número de actividades.

Las tareas diarias de hablar de lo que las víctimas y familias podrían esperar de los servicios de salud o sociales, o el sistema policial y legal se veían con frecuencia como los grandes puntos fuertes de los profesionales rurales. Un informante habló de estas actividades como algunos de los conectores importantes que podrían ocurrir en un entorno rural:

"Dar ayuda emocional, trasladar desde y hasta el hospital o tribunal...tan solo asegurándose de que los miembros de la familia estén presentes con ellos, si ellos piden ayuda adicional, son entre otras los puntos fuertes que ofrecemos".

\section{Seguimiento más allá de las situaciones graves y necesidades}

Las relaciones con la familia, cultura y fuentes referenciales para otras ayudas manifestaron atención para seguir más allá de la situación y necesidades del abuso sexual. Un informante afirmaba:

"El seguimiento de después es lo que importa... nosotros las vemos durante un corto periodo de tiempo considerando lo que va a ser toda su experiencia traumática".

De manera similar, otro trabajador de la comunidad explicó:

"Es ayuda después del hospital, después del inicio y la ayuda durante el proceso, y es la ayuda durante el proceso judicial también...y las referencias, nosotros hacemos un montón de referencias....y nosotros seguimos el caso hasta que ha terminado, especialmente la parte judicial. Quiero decir que es realmente aterrador para ellas cuando tienen que testificar"

Trabajar inter-profesionalmente y con familias fue una preocupación central de los profesionales en el cuidado de las víctimas de abusos sexuales graves. Éstas fuerzas primarias, de nuevo, se relacionan con unos valores del cuidado de la salud rural, tal y como un informante ponía en relieve: "hacer que funcione lo mejor que podamos con lo que tenemos". 


\section{Retos}

A pesar de los puntos fuertes que han sido reconocidos de las ayudas rurales y los profesionales, se han identificado muchos retos para ofrecer unos servicios mejores para los abusos sexuales rurales graves, entre los que se han identificado: incertidumbre, falta de familiaridad, constante cambio de protocolos/sistemas, confusión de papeles, dificultades personales con el interrogatorio, ambientes sociales poco sustentadores, consistencia o sustentabilidad mínima de los programas de apoyo, confianza limitada en el proceso.

Incertidumbre, falta de familiaridad, constantes cambios de protocolos/sistemas.

Las percepciones de constantes cambios de protocolos/sistemas para la evaluación, referencias y calidad de recopilación de pruebas eran preocupaciones para un cuidado bueno de los abusos sexuales y su tratamiento. Un informante afirmó:

"No las veo [víctimas de abusos sexuales] con tanta frecuencia, así que ¿cuántas personas se están equipando adecuadamente para hacer lo mejor que pueden por ellas...solo por el cuidado continuado, y sabiendo que hemos hecho todo lo que podemos?"

Otro trabajador del ámbito sanitario reforzó éste reto de falta de familiaridad, y sus dificultades permaneciendo segura y competente en sus destrezas. Ella dijo:

"Ocho años, y probablemente haya hecho alrededor de unos ocho [recopilación de muestras de abusos sexuales] conjuntos, y siempre es diferente. Siempre hay diferentes tipos de opiniones, nosotros nunca sabemos realmente. ¿Es el agente detrás de la cortina, es el de fuera? ¿Y todo esto se va a sacar del tribunal por una cosa que nosotros hicimos mal?"

La preocupación de la familiaridad y "hacer lo correcto" con frecuencia nacía de las posibles ramificaciones legales de evaluación e investigación. Una falta de familiaridad resultaba en algunos profesionales que deseaban un cuidado especializado de las víctimas en la ciudad, o replicación de servicios especializados en las áreas rurales (especialmente entrenamiento para SANEs, por ejemplo). Sin embargo, esto no disminuyó la responsabilidad que sentía la plantilla tratando a las víctimas en áreas rurales. Una enfermera de la plantilla informó este sentido de responsabilidad entre protocolos poco certeros en este comentario: "nosotros queremos saber qué es lo más reciente. Queremos hacerlo bien".

Los terapeutas estaban plagados de preocupaciones por si en la combinación de evaluaciones y entrevistas policial, enfermera/médica se pudieran perder algunas cosas por la falta de familiaridad o incluso simplemente por estar "presionados por el tiempo", que se ampliaría si uno fuera un principiante pasando el reconocimiento o recopilando las pruebas con los protocolos de violación. Sentirse apresurado, desconocido y ansiosos por las ramificaciones y probablemente para un proceso judicial posterior eran todas las notables preocupaciones. Según un administrador de la salud rural:

"Yo he tenido doctores que de hecho se niegan a hacerlos [exámenes físicos del conjunto de abuso sexual] y hay temas con eso [falta de familiaridad] y, por supuesto, el hecho de que ellos van a ser citados a juicio y que son testigos". 
También se piensa que la falta de familiaridad con los procesos provoca retrasos, añadido a la ansiedad de la víctima. Los retrasos también provocan más ansiedad para los profesionales, que estaban preocupados con las experiencias traumáticas de las víctimas. Los resultados de los retrasos podrían significar que el seguimiento no ocurriría o los pacientes abandonarían sin ver a nadie, incrementando la probabilidad de problemas relacionados con la salud mental, y dificultando la prosecución y el acceso a un cuidado de apoyo. El aumento de la educación profesional se pensó como un camino para acelerar una evaluación e investigación buena.

\section{Confusión de papeles}

Mientras las diferencias profesionales y los enfoques interdisciplinares podían ser puntos fuertes, la confusión de papeles y las diferencias profesionales también ofrecían un nivel de confusión durante el trabajo crítico. Las responsabilidades podían ser enviadas en numerosas formas dependiendo del puerto de entrada a los profesionales de abusos sexuales (policía, urgencias, comunidad de la salud, profesional general, trabajador social y así sucesivamente); un enfoque no encaja en todas las situaciones. Cada departamento tiene una plantilla diferente y las demandas pueden cambiar en cuestión de minutos, así que las tareas de rehabilitación compartidas que podían repartirse fueron identificadas. Por ejemplo, en un centro se vio la posibilidad de que las enfermeras tomasen el historial y la evaluación no genital para reducir el tiempo que el médico necesitaría en el servicio de urgencias.

Una plantilla numerosa con diferentes papeles y responsabilidades contribuía a dificultar la comunicación entre los profesionales y con las víctimas. Una trabajadora social de la comunidad rural explicó:

"Hay veces, que vengo los lunes por la mañana, y hay una referencia para seguir una víctima de abusos sexuales que no fuimos avisados. Entonces llamo a esta extraña y le digo "hey, soy de trabajo social, solo quiero ver cómo vas, ¿puedes darme luego un toque?" Eso podría ser mucho menos incómodo."

En algunas comunidades acceder a la ayuda de trabajadores sociales después de las horas normales de trabajo fue un reto.

\section{Dificultades personales con la entrevista}

La naturaleza sensible del interrogatorio del abuso sexual puede ser otra preocupación. En algunos casos, los retos emocionales para la policía eran tan grandes que los agentes deseaban que esas llamadas que atienden a abusos sexuales no resulten en una investigación completa. Esta preocupación se acentúa por las diferencias de género, por ejemplo, cuando un policía masculino joven estaba investigando el abuso de una mujer que había sido abusada por otro hombre joven. Un agente rural explicó:

"Estás hablando incluso sobre la anatomía de las mujeres, y asuntos como esos son incómodos para un montón de chicos. Si no es una chica, entonces es porque se trata de un hombre, lo que es casi tan intimidador, así que a veces los chicos [policía] deseamos que sea una llamada de nada porque no quieren tener que investigar".

Más allá de las relaciones de género, las dificultades personales con las situaciones cargadas de emociones sobre el abuso sexual son conocidas por los terapeutas. 
Tener solo una persona en la plantilla disponible podría significar que independientemente de la capacidad, el terapeuta de servicio necesitaría tomar la responsabilidad, esté o no cómodo con los aspectos emocionales. Conflictos adicionales surgen cuando los trabajadores de la salud tienen dilemas por querer ayudar a la plantilla nueva a que aprenda, facilitando el sistema de observación/orientación de preparación para doctores y enfermeras, mientras tienen que atender también la sensibilidad de las víctimas y las familias. En una experiencia recontada, una enfermera rural explicó:

"Éste [cuidado a una víctima de abuso sexual en un hospital rural] es algo que es muy personal. ¿A caso quiere esa persona tumbada sobre esa camilla otra persona tan solo observando?"

Preocupaciones adicionales sobre llevar las entrevistas de las víctimas incluían conocimiento de las preguntas clínicas adecuadas para preguntar sin interferir con la investigación policías, así como tener el conocimiento de la documentación requerida. Desarrollar estas destrezas y conocimientos se ha considerado crucial para prevenir la segunda victimización"

\section{Servicios y ambientes sociales que no son de ayuda para el seguimiento}

A veces, sutilmente o abiertamente se identificaron prácticas que no eran de ayuda. Se trataba de prácticas donde la confidencialidad o la culpabilidad de la víctima suponían riesgos para las víctimas. Un informante cuestionó el nivel de apoyo disponible en su comunidad, preguntando:

“¿Se sienten las víctimas como si ellas pudieran confiar y sentirse respetadas por la comunidad, y que lo que ocurre no se va a expandir por la comunidad como un cotilleo? Creo que es una preocupación para muchos pacientes".

Durante la discusión se observó que en algunas comunidades aborígenes el perpetrador y la víctima podían vivir próximos, o incluso en el mismo ambiente familiar, lo que podría causar disputas familiares y discordia. De acuerdo con otro informante, la falta de ayuda por parte de familiares y amigos podría significar que las víctimas podrían detener el tratamiento o la persecución, en un esfuerzo por evitar conflicto entre las familias o la comunidad.

"[la víctima] es victimizada por la familia. Así que ellas tienen la tendencia a no decir nada. No quieren abrir una lata llena de gusanos".

El material y los recursos físicos en comunidades fueron también retos para unos servicios completos en los abusos sexuales graves. En algunos casos, vivir de un modo rural, significaba que el transporte era un problema y que la víctima no tendría acceso al centro de salud o al hospital rural fácilmente tras el abuso sexual. Un trabajador de la salud de un centro rural explicó:

"Y no es solo el traslado. Es incluso la comunicación...un montón de gente incluso no tiene teléfonos para llamar a pedir ayuda". 


\section{Falta de consistencia/sustentabilidad para los programas de ayuda}

La sustentabilidad de los servicios y los programas de apoyo también eran preocupaciones importantes de los informantes. En comunidades rurales y aborígenes, el financiamiento y los mandatos cambiantes de los servicios gubernamentales y no gubernamentales resultaron ser un reto para la provisión de servicios consistentes, competentes y completos de los abusos sexuales. Un coordinador de los servicios de salud informó:

"Mi preocupación es el aspecto financiero...en las comunidades aborígenes nosotros estamos siempre buscando financiación".

Diferentes programas y servicios tenían con frecuencia diferentes mandatos, así que ofrecerles lo que un informante nombró como "paquetes de financiación o servicio" juntos podían interrumpir la provisión de un servicio consistente. Esto era cierto en las comunidades aborígenes, así como otras comunidades rurales. En muchos servicios el trabajador designado (por ejemplo, en salud mental o salud sexual) podría tener uno o dos días asignados a la semana, con frecuencia cambiantes, y el antojo de financiación y prioridades de sus servicios estarían redirigidas a otro lugar.

A veces la financiación que estaba disponible no se podía dirigir a los servicios de abusos sexuales. En otros casos, el trabajo involucrado en pedir más recursos, reduciría la actual provisión de servicios de abusos sexuales.

Un sentido de desconfianza en la comunidad en el proceso se describió consistentemente por los profesionales rurales. Brechas potenciales en la confidencialidad y privacidad se identificaron por los profesionales como uno de los aspectos de desconfianza. Un profesional aborigen afirmó:

"Siempre existe ese miedo que nuestros clientes tienen de que van a salir y van a sentir que todo el mundo...la preocupación sobre la re-victimización es muy alta. Esto ocurre en la nación [Primera reserva Nacional] todo el tiempo, especialmente con el abuso sexual".

Se sospechaba que los miembros de la comunidad tenían miedo de pedir asistencia a la policía o acusación porque sentían que no merecía la pena correr los riegos personales. El riesgo se veía mayor cuando las víctimas pensaban que ellas tendrían control en el proceso. De acuerdo con un profesional:

"Para ir a través de un evento como es ese [abuso sexual], y tener que venir después a hablar con...quiero decir, la policía intimida...tener que dar detalles tan íntimos, personales, embarazosos a un extraño que está recopilando pruebas. Después ir al proceso médico, otra recopilación de pruebas muy invasiva, de nuevo ser reexaminada en juicio, si se va a juicio. Es simplemente horrible..."

La realidad de la familiaridad en las comunidades rurales complicaba las experiencias de re-victimización y el agente de policía, enfermero o médico podían ser todo el personal asociado a la víctima, o podía haber habido un historial previo con estas asociaciones- buenas o malas. 


\section{Recursos Educativos}

Alguna de las prioridades identificada para manejar los retos fueron: saber la mayor información crucial para documentar y recopilar las pruebas, consideraciones de quién debería recibir educación y/o la audiencia prioritaria/ dirigida para los recursos educativos, un proceso rutinario/integrado para actualizar (para incluir actualizaciones sobre los recursos de seguimiento), así como la consideración de la cultura y alfabetización. Las modalidades clave identificadas para el reparto de materiales educativos incluían imprimir (breve lista con información más detallada), base web, video, y asesor en enfoques de llamada.

Con poca plantilla, la amplia preparación en estas preocupaciones especiales era más deseada que tener un "especialista" que podía estar o no disponible cuando la desgracia del abuso sexual ocurriera. "Todos nosotros necesitamos [educativos] recursos para hacerlo de la manera correcta" era la petición repetida desde los terapeutas, y como un profesional comentaba:

"Nosotros tenemos principalmente preguntas procedimentales. No tenemos problemas con las heridas, o los cuidados. Se trata de hacerlo del modo correcto."

Entre las tareas importantes procedimentales estaban: "evaluación de salud", y según la imposición del punto de vista de la ley la seguridad de las pruebas recopiladas. Los procesos consistentes de cuidados se vieron cruciales para la educación de los terapeutas. Este énfasis en clarificar las expectativas procedimentales estaba centrado en la recopilación de pruebas y documentación. Las fuentes educativas necesitarían actualización regular y una plantilla requeriría continuados recordatorios y avisos para integrar este conocimiento a las nuevas destrezas.

Las estrategias para los recursos educativos necesitan estar disponibles en un número de formatos diferentes. Esto se enfatizó por los terapeutas Aborígenes que dijeron:

"Necesitamos estar seguros de que tenemos a toda la población, o grupo de objetivo cubierto, desde los niños a los analfabetos, a los discapacitados, o a los minusválidos, a los mayores, mujeres, hombres y adolescentes".

Abrumadoramente, el enfoque preferido fue la recopilación de fuentes escritas con simples listas centradas en aspectos procedimentales de servicios inmediatos de abuso sexual. Recursos basados en páginas web también fueron apoyados por los informantes. Un enlace de una página web estaba visto como un lugar para almacenar fuentes escritas y listas que podían ser actualizadas como se requiriesen. Otras fuentes, por ejemplo videos o podcasts, estaban considerados como medios útiles para la educación en servicios de abuso sexual. Una enfermera rural afirmó:

"El teléfono es lo más fácil...ojalá pudieras tener esa conversación en el momento...ojalá tuviésemos un experto disponible".

Un asesor telefónico no era la estrategia pretendida para eliminar responsabilidad profesional, sino más para ofrecer un recurso, un suplemento a otros recursos educativos. Mantener la actualidad profesional y atender a las actualizaciones educativas no era siempre sencillo o estaba internamente motivado por algunos profesionales. Para algunos profesionales, especialmente médicos, sin 
compensación, la enseñanza que no estaba bajo mandato se percibía como un reto potencial de tal modo que la combinación de ayuda en tiempo real y los recursos de preparación educativa y listas sencillas de comprobación eran siempre deseadas.

\section{DISCUSIÓN Y RECOMENDACIONES}

Los puntos fuertes de la salud rural y los servicios profesionales de la comunidad se vieron como una profunda preocupación y compromiso para las mujeres que habían experimentado abuso sexual. La cercanía, la colaboración, la conciencia cultural y comunidad e iniciativa fueron todos identificados como puntos fuertes de los servicios para el abuso sexual rural. Varios retos de provisión de servicios de abuso sexual grave también fueron identificados, incluyendo la falta de familiaridad y plantilla actual, cambiando los protocolos/sistemas, confusión de roles, dificultades personales con el interrogatorio, ambientes no conductivos para un seguimiento y servicios inconsistentes y financiación. Alguna de estas prioridades principales para los recursos educativos incluía: saber la información más crucial para documentar y recopilar como pruebas, consideraciones de quién debía recibir la información y/o la audiencia prioritaria para los recursos educativos, y un rutinario/integrado proceso de actualizar esos recursos, así como la consideración de la cultura y alfabetización.

Parecía que existía un énfasis mayor en los terapeutas hacia los protocolos de recopilación de pruebas más que en los servicios completos de abusos sexuales. Sin embargo, no todas las mujeres eligen informar a la policía o a los servicios sanitarios ${ }^{1}$, y la capacidad para elegir informar es esencial para la recuperación y consistencia de nuestro marco de trabajo de feminismo crítico que reduce las desigualdades de poder. El aislamiento y falta de transporte a los centros urbanos no debe forzar a la mujer a informar a la policía y por consiguiente ser sujeto de procedimientos de recopilación de pruebas de abusos sexuales que pueden re-victimizar al superviviente del abuso sexual ${ }^{2}$.

Aunque solo hay un tipo de conjunto de pruebas de abuso sexual con instrucciones estandarizadas, los cambios de estos procedimientos no han sido uniformemente comunicados a los profesionales. También hay una variabilidad por la región basada en los fiscales de la corona locales, previa experiencia de médicos y enfermeros y diferencias interpretando conceptos tales como cadena de custodia. Nosotros escuchamos a la plantilla pidiendo como "permiso" así como quién tendría permiso para documentar el registro de abuso sexual $u$ obtener pruebas, y miedos a que las pruebas fuesen desestimadas como resultado de sus acciones o inactividad. La plantilla pidió listas por escrito sobre los roles, tanto por ser una referencia rápida como para poder verificar que ellos estaban permitidos para llevar a cabo esos roles. Unas herramientas así podrían facilitar la redistribución de los roles de la plantilla para acomodar contextos locales y necesidades de la plantilla.

Estas áreas de incertidumbre, y de deseo expresado para recursos educativos y consejeros en tiempo real, son instructivos para esos servicios de coordinación y el desarrollo educativo de enfermería y del personal. Mientras que un servicio efectivo, SANEs especializados puede no ser siempre la respuesta en todas las comunidades. ${ }^{1}$ Los procedimientos básicos del cuidado y examen para el abuso sexual no deben percibirse como algo más allá del ámbito del practicante medio. Últimamente, los generalistas quienes están de hecho disponibles y más capacitados para ofrecer un cuidado compasivo y completo en las comunidades rurales, esos servicios de salud y sociales y plantilla policial "haciendo lo mejor que podemos con lo que tenemos". 


\section{CONCLUSIONES}

El completo cuidado del abuso sexual incluye intervención en el momento de crisis, previsiones para la seguridad, una evaluación completa con un tratamiento preventivo para el embarazo y otras enfermedades comunes de transmisión sexual, la capacidad de informar a la policía con la recopilación de pruebas si son necesarias, y acceso a los servicios de asesoramiento para el seguimiento. Los médicos de emergencia y enfermeras, policías y otros apoyos comunitarios tienen experiencia en la prestación de servicios. Estas habilidades pueden ser un activo en el cuidado del abuso sexual, incluso dentro de un entorno rural, donde los recursos son limitados. Apoyar la capacidad de los terapeutas rurales a través de recursos educativos para mejorar sus capacidades para ofrecer servicios integrales de agresión sexual es una prioridad para la reducción de los riesgos de victimización secundaria y otros impactos en la salud mental.

\section{REFERENCIAS}

${ }^{1}$ United Nations (2010). The World's Women 2010: Trends and Statistics- Chapter 6: p127-140. ST/ESA/STAT/SER.K/19. United Nations - Department of Economic and Social Affairs, New York, USA. http://unstats.un.org/unsd/demographic/products/Worldswomen/WW2010\%20Report by\%20chapter(pdf)/violence\%20against\%20women.pdf.

2 Johnson, H. (2006). Measuring violence against women: Statistical trends 2006. Ottawa: Statistics Canada.

${ }^{3}$ Lewis, S. H., \& Reed, E. (2011). Sexual assault in rural communities. Retrieved July 22, 2012, from http://www.vawnet.org/printdocument.php?doc id=419\&find type $=$ web desc AR

4 Jones, J. S., Alexander, C., Wynn, B. N., Rossman, L., \& Dunnuck, C. (2009). Why women don't report sexual assault to the police: The influence of psychosocial variables and traumatic injury. The Journal of Emergency Medicine, 36(4), 417-424. Retrieved from http://search.ebscohost.com/login.aspx?direct=true\&AuthType=ip,url,cookie, uid\&db=c medm\&AN=18462905\&site=ehost-live

${ }^{5}$ Federal Provincial Territorial Ministers. (2002). Assessing violence against women: A statistical profile

${ }^{6}$ Carter-Snell, C., \& Hegadoren, K. (2003). Stress disorders and gender: Implications for theory and research. Canadian Journal of Nursing Research, 35(2), 34-55.

${ }^{7}$ Foa, E. B., \& Street, G. P. (2001). Women and traumatic events. Journal of Clinical Psychiatry, 62(Suppl 17), 29-34.

8 Carter-Snell, C., Jakubec, S.L. (2013). Exploring Influences on Women's Mental Health after Interpersonal Violence. The International Journal of Child, Youth and Family Studies, 1:72-99.

${ }^{9}$ Campbell, R., Wasco, S. M., Ahrens, C. E., \& Sefl, T. B. H. E. (2001). Preventing the 'second rape': Rape survivors' experiences with community service providers. Journal of Interpersonal Violence, 16(12), 1239-1259.

${ }^{10}$ Campbell, R. (2008). The psychological impact of rape victim's experiences with the legal, medical and mental health systems. American Psychologist, 63(8), 702-717.

11 Decker, S. E., \& Naugle, A. E. (2009). Immediate intervention for sexual assault: A review with recommendations and implications for practitioners. Journal of Aggression, Maltreatment \& Trauma, 18, 419-441. 
12 Fehler-Cabral, G., Campbell, R., \& Patterson, D. (2011). Adult Sexual Assault Survivors' Experiences with Sexual Assault Nurse Examiners (SANEs). Journal of Interpersonal Violence, 26(18), 3618-3639.

${ }^{13}$ Taylor, S. C. \& Gassner, L. (2010). Stemming the flow: challenges for policing adult sexual assault with regard to attrition rates and under-reporting of sexual offences, Police Practice and Research, 11(3)240-255.

${ }^{14}$ Regan, L. \& Kelly, L. (2003) Rape: Still a Forgotten Issue, Briefing Document for Strengthening the Linkages - Consolidating the European Network Project, London: Child \& Woman Abuse Studies Unit. Available at: http://www.rcne.com/downloads/RepsPubs/Attritn.pdf.

${ }^{15}$ World Health Organization. (2010). Sexual Violence Research Initiative: Report of Evaluation Findings. WHO, Geneva. Retrieved from: http://www.svri.org/Evaluation2010Report.pdf

${ }_{16}$ Native Women's Association of Canada (2007).Fact Sheet: Violence Against Aboriginal Women, NWAC, Ottawa, Canada. Retrieved from

http://www.nwac.ca/sites/default/files/imce/NWAC 3E Toolkit e.pdf

17 Zinzow, H., \& Thompson, M. (2011). Barriers to reporting sexual victimization: Prevalence and correlates among undergraduate women. Journal of Aggression, Maltreatment \& Trauma, 20(7), 711-725. doi:10.1080/10926771.2011.613447

${ }^{18}$ Averill, J. B., Padilla, A. O., \& Clements, P. T. (2007). Frightened in isolation: Unique considerations for research of sexual assault and interpersonal violence in rural areas. Journal of Forensic Nursing, 3(1), 42-46. Retrieved from http://search.ebscohost.com/login.aspx?direct=true\&AuthType=ip,url,cookie,uid\&db=c medm\&AN $=17479565 \&$ site $=$ ehost-live

${ }^{19}$ Lamont, W. (2006). Sexual assault services in Alberta: A framework of service delivery for sexual assault survivors living rural, remote and northern communities. Calgary, AB: Alberta Association of Sexual Assault Centers.

20 Campbell, R., Patterson, D., Adams, A. E., Diegel, R., \& Coats, S. (2008). A participatory evaluation project to measure SANE nursing practice and adult sexual assault patients' psychological well-being. Journal of Forensic Nursing, 4(1), 19-28.

${ }^{21}$ Canadian Association of Emergency Physicians. (2004). The Canadian triage \& acuity scale (CTAS) for emergency departments. Retrieved from: http://caep.ca/resources/ctas

${ }^{22}$ Campbell, R. (2006). Rape survivors' experiences with the legal and medical systems. Violence Against Women, 12(1), 30-45.

${ }^{23}$ Bramsen, R. H., Elklit, A., \& Nielsen, L. H. (2009). A Danish model for treating victims of rape and sexual assault: The multidisciplinary public approach. Journal of Aggression, Maltreatment \& Trauma, 18(8), 886-905. doi:10.1080/10926770903291811

24 Royse, B. (1999). Non-stranger sexual assault: Rural realities. Denver Sexual Assault Interagency Council-National Non-Stranger Sexual Assault Symposium, Proceedings Report, Denver, CO. 12-15.

${ }^{25}$ Tutty, L., Jesso, D., McDonald, B., \& Smit, D. (2005). Environmental scan of alberta services to address sexual assault and sexual abuse. (). Calgary, AB: Alberta Association of Sexual Assault Centers.

${ }^{26}$ Moosa-Mitha, M. (2005). Situating anti-oppressive theories within critical and difference-centered perspectives. In L. Brown, \& S. Strega (Eds.), Research as resistance: Critical, indigenous and anti-oppressive approaches. (pp. 37-72). Toronto: Canadian Scholars Press.

${ }^{27}$ Flick, U. (2006). An introduction to qualitative research (3rd ed.). Thousand Oaks: Sage. 
${ }^{28}$ Sandelowski, M. (1986). The problem of rigor in qualitative research. Advances in Nursing Science, 8(3), 27-37., 8(3), 27-37.

${ }^{29}$ Lincoln, Y. S., \& Guba, E. G. (1985). Naturalistic inquiry. London: Sage.

${ }^{30}$ Patterson, D., Greeson, M., \& Campbell, R. (2009). Understanding rape survivors' decisions not to seek help from formal social systems. Health \& Social Work, 34(2), 127.

${ }^{31}$ Campbell, R. (2005). What really happened? A validation study of rape survivors' help-seeking experiences with the legal and medical systems. Violence \& Victims, 20(1), 55-69.

${ }^{32}$ Campbell, R., Patterson, D., \& Lichty, L. F. (2005). The effectiveness of sexual assault nurse examiner (SANE) programs. Trauma, Violence \& Abuse, 6(4), 313-329. 